\title{
DOG FEEDING TEST FOR ASSESSING THE NUTRITIONAL ADEQUACY OF PRACTICAL DIETS
}

\author{
M. HEGEDƯs 1 , S. FEKETE ${ }^{1 *}$, F. JANZA ${ }^{3}$, L. ZÖLDÁG ${ }^{1}$ and T. GAÁL ${ }^{2}$ \\ ${ }^{1}$ Department of Animal Breeding, Nutrition and Laboratory Animal Science; ${ }^{2}$ Department \\ and Clinic of Internal Medicine, University of Veterinary Science, H-1400 Budapest, \\ P.O. Box 2, Hungary; ${ }^{3}$ Hungarian Police, Dog Training School, Dunakeszi, Hungary
}

(Received March 24, 1999; accepted October 20, 1999)

\begin{abstract}
The nutritive value of dog foods declared by the manufacturer as nutritionally complete and balanced can be best assessed by feeding trials with dogs. A protocol of a feeding trial has been developed and tested with working dogs fed two different commercial complete and balanced diets for 8 weeks. The parameters used for evaluating the effect of diets were general health status, body and hair coat condition, change of body weight, haematological parameters (white blood cell (WBC) count, red blood cell (RBC) count, haemoglobin, packed cell volume), and biochemical parameters in blood serum (alanine aminotransferase, urea, albumin). The trial protocol proved to be appropriate to monitor the dogs' nutritional status and to reveal differences between diets. This method of evaluation is recommended for use in supporting the nutritional claims (labelling) of dog foods.
\end{abstract}

Key words: Dog foods, assessment of nutritional adequacy, feeding test

Although commercial dog foods have been available for many years, the methodology of assessing their nutritional adequacy is still a matter of discu ssion (Hegedüs, 1996). Basically there are two methods for substantiating the nutritional adequacy of 'complete and balanced' dog foods which presumably contain all the nutrients the animal needs (Case et al., 1995). In the first method the levels of all essential nutrients are declared, which should correspond to re commended nutrient allowances (e.g. AAFCO, 1991). The second method is to run a feeding trial with dogs according to a standardized procedure and to assess the nutritional status of the dogs. However, the choice of parameters and met hods that can be used for evaluating the nutritional status is the subject of scie ntific debates (Crenshaw, 1998).

Our purpose was to develop and suggest a specified protocol for assessing the nutritional adequacy of dog foods in a feeding test. The trial protocol was tested with working police dogs.

*Corresponding author. E-mail: Safekete@univet.hu; Fax: +36 (1) 4784128 
HEGEDÜS et al.

\section{Materials and methods}

Diets

Two commercial dog food products were tested. The diets are designated with the letters 'A' and 'B', because the main objective of the study was to evaluate the method of assessment of nutritional adequacy rather than to $\mathrm{d}$ escribe the two products. Both products were claimed to be nutritionally complete and balanced. The declared nutrient profiles of the foods were as fo llows:

\begin{tabular}{lcc}
\hline & Food A & Food B \\
\hline Moisture $(\mathrm{g} / 100 \mathrm{~g})$ & 10 & 10 \\
Crude protein $(\mathrm{g} / 100 \mathrm{~g})$ & 27 & 25 \\
Ether extract $(\mathrm{g} / 100 \mathrm{~g})$ & 15 & 13 \\
Crude fibre $(\mathrm{g} / 100 \mathrm{~g})$ & 3 & 3 \\
Crude ash $(\mathrm{g} / 100 \mathrm{~g})$ & 8 & 8 \\
$\mathrm{Ca}(\mathrm{g} / 100 \mathrm{~g})$ & 1.5 & 1.1 \\
$\mathrm{P}(\mathrm{g} / 100 \mathrm{~g})$ & 0.9 & 0.9 \\
$\mathrm{NaCl}(\mathrm{g} / 100 \mathrm{~g})$ & 0.6 & 0.4 \\
\hline
\end{tabular}

Both diets were supplemented with vitamins and minerals adequate to meet the requirements of the dogs, according to the claims of the manufacturers. The same formulas were used throughout the test. One of the diets had prev iously been used at the police dog training centre, and served as control.

The analysed nutrient content of the two diets corresponded well to the declared values.

\section{Animals}

All dogs were of the German Shepherd breed, healthy, male, over one year of age, and had optimal body weights. Each dog starting the test had passed a physical examination by a veterinarian for general health status as well as body and hair coat condition. The test and the control groups (Group A and Group B) were formed randomly and consisted of eight animals each.

\section{Experimental design}

The feeding trial was performed at the central dog training facilities of the national police (Dunakeszi, Hungary), and was run for eight weeks to assess the nutritional adequacy of the diets for working dogs. The dogs were housed ind ividually in separate kennels. The daily food intake was $700 \mathrm{~g} / \mathrm{dog}$ based on the expectable energy requirement of the dogs (Lewis and Morris, 1984; Burger, 1994). Fresh tap water was provided ad libitum. The dogs were adapted to the 
test diet by supplying it in increasing ratio to the previous diet for one week. I ndividual body weights were measured at the beginning, weekly and at the end of the trial at the same hour. Daily feed consumption was measured and recorded. The consistency of the faeces was evaluated according to its form and appea rance. All the dogs participated in the daily training routine.

\section{Blood profile analysis}

A series of blood tests was done to identify possible abnormal processes. Individual blood samples were taken at the start and at the end of the feeding trial. Haematology values such as white blood cell ( WBC) count, red blood cell (RBC) count, haemoglobin, and packed cell volume ( PCV) were determined by the use of a Twincell semi-automatic analyzer (Diatron Kft, Hungary) using a modified sof tware for dogs. Serum biochemistry profiles (alanine aminotransferase, urea, alb umin) were determined with a commercial kit supplied by Diagnosticum Kft (Hungary). MS Excel 5.0 software (Microsoft) was used for statistical processing of the data to demonstrate significant differences between the mean values.

\section{Results}

Each dog performed the feeding test with success, with no intercurrent di seases or injuries. Weekly individual body weight of the dogs during the feeding experiment and relative weight changes are shown in Table 1. The individual and mean closing body weights were expressed in percentage, taking the corresponding starting weights as $100 \%$. Mean body weight of the groups with standard deviation (SD) and coefficient of variation (CV) of the values are also indicated.

All dogs fed diet A were able to increase their body weights during the feeding trial; however, the increase in mean body weight between starting and closing values was not significant $(\mathrm{p}>0.05)$. The mean body weight of the dogs fed diet $\mathrm{B}$ did not change between the start and the end of the feeding trial; ho wever, four dogs lost some weight. Based upon the measured body weights, both diets were considered appropriate for working dogs; however, diet A proved to be somewhat superior to diet B.

Haematological and biochemical parameters of blood samples at the start and at the end of the feeding trial are summarized in Table 2. All parameters fell within the normal ranges suggested for dogs. Statistical evaluation of the data showed si gnificant increase $(\mathrm{p}<0.05)$ in red blood cell count and haemoglobin level in dogs fed $\operatorname{diet} \mathrm{A}$ as compared to the starting values; however, packed cell volume also i ncreased, which can partially explain this finding. There were no significant diffe $r-$ ences between the groups in mean biochemical values. On the basis of the haemat ological parameters, serum alanine aminotransferase, urea and albumin values both $\mathrm{d}$ iets were considered to be nutritionally complete for working dogs. 


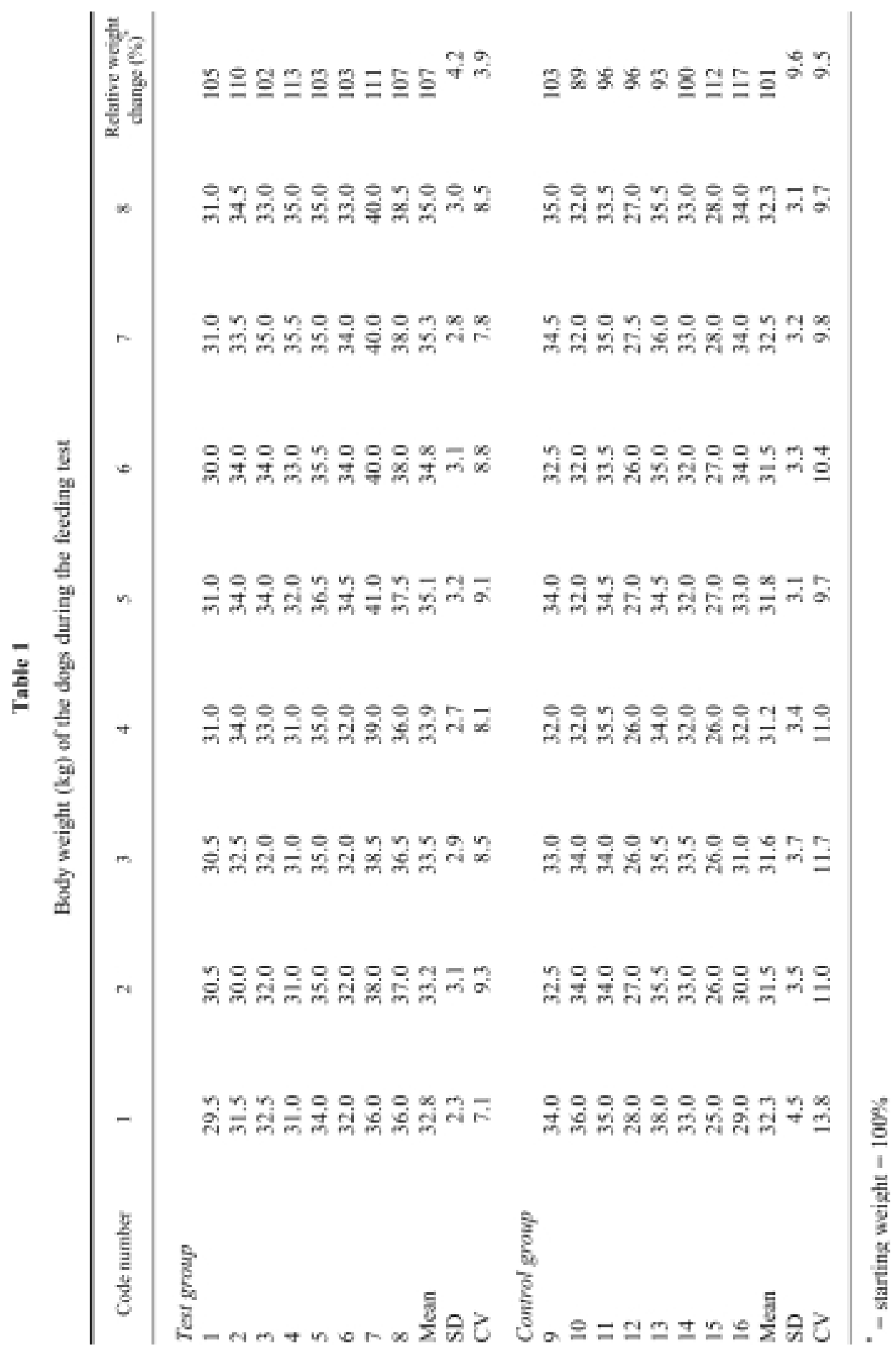




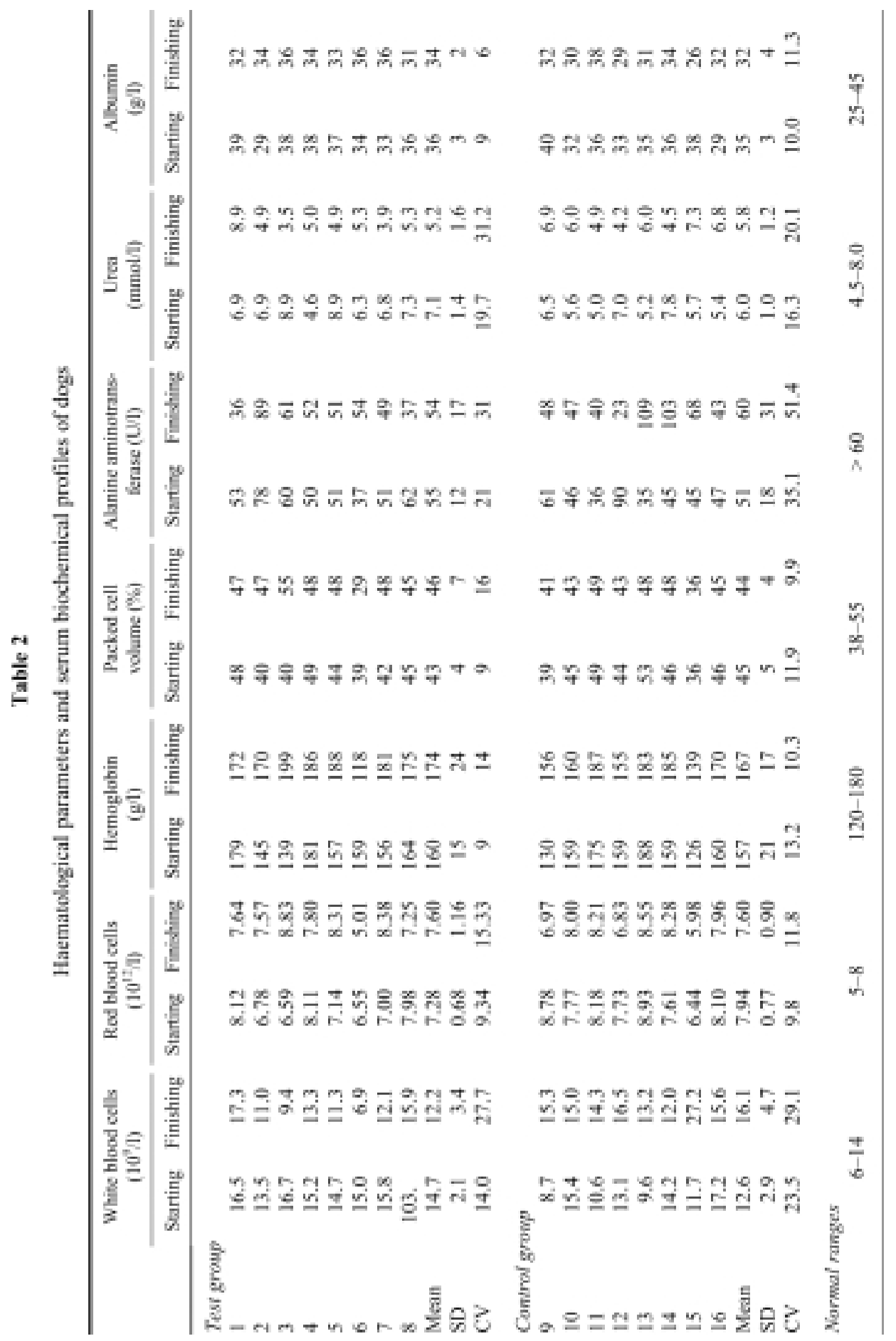


HEGEDÜS et al.

\section{Discussion of the method}

\section{Which parameters to measure?}

The general suggestions of the AAFCO feeding test (AAFCO, 1993) were accepted; however, some modifications regarding the parameters to be measured were applied. Each dog must be evaluated by a veterinarian at the beginning and at the end of the feeding test for general health status as well as body and hair coat condition, and comments shall be recorded. A body condition scoring sy stem may be used to evaluate emaciated, thin, underweight, ideal, overweight, heavy and obese animals (Fekete and Vörös, 1994; Laflamme et al., 1995). Any medication and the reason for its use must also be recorded. Less than $25 \%$ of the dogs may be removed from the test for non-nutritional reasons. Pathological examination must be conducted on dogs that die during the test.

Body weight measurements supply important information regarding the overall nutritive value of the diets. If the nutritional claim is to be obtained for adult maintenance, loss of weight or increasing obesity may indicate inappropr iate energy density of the diet. In the case of working dogs weight loss should be avoided.

Metabolic profile analysis can provide useful information for nutrition $\mathrm{r}$ esearch studies, but interpretation of the values requires care and attention. The haematological values and serum parameters are related to the general health of the animals, however, diets may have some potential for changing metabolic processes in the body (Rosenberg, 1994). Whether the deviation of a parameter from the normal range is the consequence of an illness or that of the diet must be established by a veterinary examination of the animal. Normal ranges of the $\mathrm{p}$ arameters should be determined by examining a normal population of the tested dog breed, using the results of the same laboratory to obtain compar able values.

The WBC count is an indication of intercurrent infection of the exper imental animals. A normal leukocyte count shows that the animals are healthy. RBC, haemoglobin and PCV values are related to the oxygen-carrying capacity of the blood and thus to the overall vitality of the dogs. Serum alanine amin otransferase activity (ALT) may be an important measure of liver cell injury which may be related to the diet. The overall protein nutritional status can be monitored on the basis of the serum albumin levels; however, the slow turnover requires that this parameter be evaluated at least at one-month intervals. Serum urea may change according to quantitative and qualitative protein intake. If the albumin levels are in the normal range, low serum urea values indicate high biological value of the dietary protein. 


\section{Rationed or ad libitum feeding}

For assessing the nutritional adequacy of dog foods for growth and lact ation ad libitum feeding is recommended, while for maintenance restricted fee ding is more appropriate to avoid possible overeating and the development of obesity. For working dogs both ad libitum and calculated feed intake may be used according to their body condition.

\section{Interpretation of the results}

The diet is acceptable if no dogs show clinical or pathological signs of $\mathrm{n} \mathrm{u}$ tritional deficiencies or excesses. If no control group is used, the average body weight change in percentage of the starting weight should be zero minus the allo wance for normal variation according to the one-tailed $t$-test at $\mathrm{p}=0.05$. If a test group is compared with a control group, one-tailed two sample $t$-test at $\mathrm{p}=0.05$ should be used for detection of significant differences between the mean va lues.

No adult dog is allowed to change more than $15 \%$ of its initial body weight. The same can be applied for the values of blood profile tests.

\section{Conclusions}

The nutritive value of dog foods claimed by the manufacturer as nutritio nally complete and balanced can be best assessed by a feeding trial. The su ggested parameters for evaluating the effect of the diet are :

- general health status, body and hair coat condition;

- body weight change;

- haematological parameters (WBC and RBC count, haemoglobin, PCV); albumin).

- biochemical parameters in blood serum (alanine aminotransferase, urea,

An at least eight-week feeding period is recommended for evaluating dog foods for maintenance or work. If other claims are to be obtained (for growth or for lactation), the whole physiological time period must be a ssessed.

This feeding trial protocol was tested with working dogs and proved to be appropriate for monitoring the dogs' nutritional status and for revealing diffe rences between two diets. Thus, the test protocol can be recommended for use in substantiating the nutritional claims of dog foods.

\section{Acknowledgements}

This research was partly sponsored by the Hungarian Scientific Research Fund (OTKA, project numbers T 025821 and T 026606). The authors would like to thank the co-operation and activity of Z. Szilágyi and A. Kovács in the feeding trial and of Miss K. Jaksics in the laboratory works. 
HEGEDÜS et al.

\section{References}

AAFCO (1991): Association of American Feed Control Officials. Official Publication, AAFCO, Inc., Atlanta, GA.

AAFCO (1993): Association of American Feed Control Officials. Official Publication, AAFCO, Inc., Atlanta, GA.

Burger, I. (1994): A basic guide to nutrient requirements. In: Burger, I. (ed.) The Waltham Book of Companion Animal Nutrition. Pergamon Press, Oxford, pp. 5-26.

Case, L. P., Carey, D. and Hirakawa, D. A. (1995): Canine and Feline Nutrition. Mosby-Year Book, Inc., St. Louis, p. 155.

Crenshaw, T. A. (1998): Pet food product family guidelines and affidavits. In: Fourth Annual Pet Food Regulations Educational Workshop. St. Louis, Nov. 12-15.

Fekete, S. and Vörös, K. (1994): Canine and feline dietetics, with special regard to the nutrition of diseased and old animals (in Hungarian, with English abstract). Magyar Állatorvosok Lapja 49, 733-738.

Hegedüs, M. (1996): The use of commercial pet foods in the nutrition of dogs and cats. Assessment of the nutritional adequacy of pet foods (in Hungarian, with English abstract). Magyar Állatorvosok Lapja 51, 552-559.

Laflamme, D. P., Kuhlman, G., Lawler, D. F., Kealy, R. D. and Schmidt, D. A. (1995): Obesity management in dogs. In: Veterinary Clinical Nutrition. Purina Forum on Small Animal Nutrition. Brillig Hill Inc., Santa Barbara, pp. 9-14.

Lewis, L. D. and Morris, M. L. (1984): Small Animal Clinical Nutrition. Mark Morris Associates, Topeka, Kansas, USA, p. 7.

Microsoft (1995): User's Guide, Microsoft Corporation.

Rosenberg, I. H. (1994): Nutrient requirements for optimal health: what does that mean? J. Nutr. 124, $1777 \mathrm{~S}$. 